\title{
Thermal Conductivity of Three-Dimensionally Interconnected Graphene-Networked Cu Composite Fabricated by a Simple Two-Step Process
}

\author{
Xue $\mathrm{Li}^{1}$, Terry Arthur Ring ${ }^{2}$, and Byung-Sang Choi ${ }^{1,3, *}$ \\ ${ }^{1}$ Department of Materials Science and Engineering, Chosun University, Gwangju 61452, Republic of Korea \\ ${ }^{2}$ Department of Chemical Engineering, University of Utah, Salt Lake City, UT 84108, USA \\ ${ }^{3}$ Micro \& Nano Technologies, Inc., Gwangju 61452, Republic of Korea
}

\begin{abstract}
A Cu composite reinforced by a three-dimensionally interconnected graphene network was synthesized in situ by a simple two-step process utilizing compacted $\mathrm{Cu}$ powder ( $99 \%$ purity) as a template for the growth of graphene. $\mathrm{Cu}$ composites with different graphene contents were obtained by controlling the processing parameters. The composites were approximated to have two layers of graphene with curved shapes, high aspect ratios, and which were wrapped around $\mathrm{Cu}$ grains at the grain boundaries. The threedimensionally interconnected graphene structure formed throughout the $\mathrm{Cu}$ matrix can act as a barrier to $\mathrm{Cu}$ diffusion and dislocation movement. Enhanced thermal conductivities (TCs) of $406 \pm 5 \mathrm{~W} / \mathrm{mK}$ and $385 \pm$ $7 \mathrm{~W} / \mathrm{mK}$ in the through- and in-plane directions, respectively, were obtained at room temperature for the $\mathrm{Cu}$ composite with a disc density of $8.16 \mathrm{~g} / \mathrm{cm}^{3}$ and carbon content of $\sim 73 \mathrm{ppm}$. The lower in-plane TC as compared to the through-plane TC could be explained by the increased number of defects as the measurement distance increased from $0.9 \mathrm{~mm}$ (through-plane) to $13 \mathrm{~mm}$ (in-plane). In conclusion, the spatial distribution of the three-dimensionally interconnected continuous graphene network throughout the $\mathrm{Cu}$ matrix must provide effective pathways for thermal conduction in the $\mathrm{Cu}$ composite, to thereby enable relatively high thermal conduction.
\end{abstract}

(Received May 22, 2019; Accepted July 3, 2019)

Keywords: graphene-Cu composite, 3D-interconnected graphene, $\mathrm{Cu}$ powder, chemical vapor deposition

\section{INTRODUCTION}

There have been several studies thus far utilizing graphene as a filler to improve the mechanical, electrical, and thermal properties of polymer and metal matrices [1-15]. To maximize the contribution of graphene to the thermal conductivity (TC) of a matrix, it is well known that in addition to a well-ordered alignment and uniform dispersion, a continuous graphene network in the matrix is also essential $[16,17]$. These conditions are key to improving the TC of graphene/metal composites while simultaneously minimizing interfacial thermal resistance along the alignment direction [18-20]. In addition, an understanding of $\mathrm{C}$ diffusion in $\mathrm{Cu}$ and its behavior at the $\mathrm{Cu} / \mathrm{C}$ interface is fundamental to

\footnotetext{
- Xue Li: 박사과정, Terry Arthur Ring · Byung-Sang Choi: 교수

*Corresponding Author: Byung-Sang Choi

[Tel: +82-62-230-7190, E-mail: bschoi@chosun.ac.kr]

Copyright (C) The Korean Institute of Metals and Materials
}

developing successful strategies for improving the performance of graphene-metal matrix composites [21-24].

Despite the extensive research on the subject, current fabrication methods for graphene-metal matrix composites involve complicated processes and expensive equipment, making the industrial use of these materials difficult. In a recent report, we introduced a simple in situ two-step fabrication route for a three-dimensionally interconnected graphene-networked $\mathrm{Cu}$ (3DiGn-Cu) composite with a curved shape, high aspect ratios and widths, and graphene platelets/sheets that are bent, anchored, and often wrapped around metallic grains at grain boundaries [25]. It has been known that graphene sheets, which have a large contact area with the metallic matrix, provide effective load transfer [26]. Additionally, the graphene wrapped around metallic grains in metal-graphene composites provides good corrosion resistance to the metallic matrix, with five- fold better stabilities in a corrosive environment compared to the metal without graphene [27]. 
As reported in our previous study [25], a 3DiGn-Cu composite was fabricated by a new and simple two-step fabrication route: axial compaction of $\mathrm{Cu}$ powder followed by chemical vapor deposition (CVD). In this work, we demonstrate the highest TC obtained thus far for the 3DiGn$\mathrm{Cu}$ composite using compacted $\mathrm{Cu}$ power (99\% purity) as a template for the growth of $3 \mathrm{D}$ graphene.

\section{EXPERIMENTAL}

\subsection{Preparation of $\mathrm{Cu}$ discs}

$\mathrm{Cu}$ powder (99\% purity) was purchased from Aldrich and used as received. Scanning electron microscopy (SEM) images of the powder are shown in Fig. 1, with spheroidal particles of $14 \sim 25 \mu \mathrm{m}$ in size. Figure 1 (b) is a magnified image of the box in (a) to show the pores on the particle surfaces. Without any additives, $\mathrm{Cu}$ discs $(15 \mathrm{~mm}$ in diameter and $1.3 \pm 0.1 \mathrm{~mm}$ in thickness) were prepared using $1.4 \pm 0.15 \mathrm{~g}$ of $\mathrm{Cu}$ powder at different compaction pressures in the range of $1500 \sim 5000 \mathrm{~kg}$. Axial compression was applied to the $\mathrm{Cu}$ powder in a mold using a double-action oil hydraulic press.

The SEM images in Fig. 2 show the exposed fractured surface of a compacted $\mathrm{Cu}$ disc sample after it was cut in half. The images show good mechanical interconnections
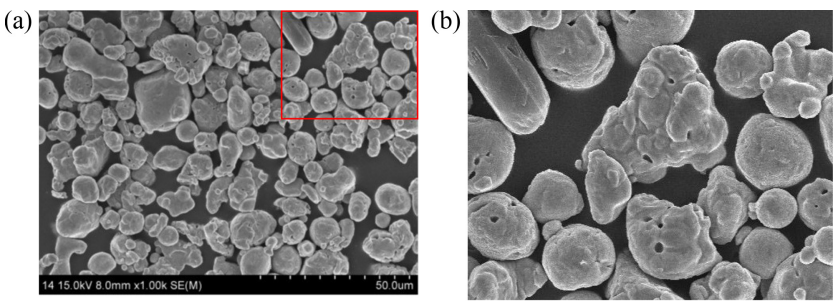

Fig. 1. (a) SEM image of $\mathrm{Cu}$ particles (diameter $=14 \sim 25 \mu \mathrm{m}$ ) and (b) magnified image of box in (a) to show the porous particle surfaces.

(a)

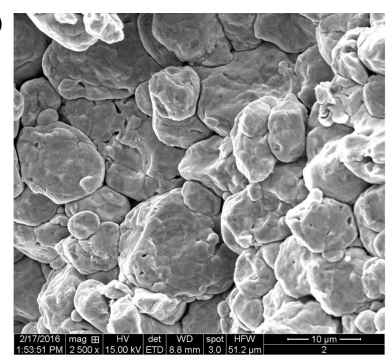

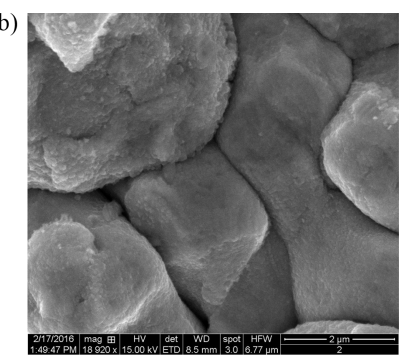

Fig. 2. SEM images showing the exposed fractured surface of a compacted $\mathrm{Cu}$ disc after it was cut in half. between the $\mathrm{Cu}$ particles after compaction in a mold. In addition, the shape of the $\mathrm{Cu}$ particles, as shown in Fig. 2(b), changed from spheroidal to somewhat angular-shaped, which is an indication of the particles experiencing some degree of plastic deformation during compaction.

\subsection{Synthesis of three-dimensionally interconnected graphene-networked $\mathrm{Cu}$ (3DiGn-Cu) composite}

The CVD apparatus used in this work had a gas distribution system consisting of $\mathrm{H}_{2}(99.999 \%)$ and $\mathrm{CH}_{4}$ (99.995\%) flowing through each mass flow controller into a quartz tube furnace $1.5 \mathrm{~m}$ long and $80 \mathrm{~mm}$ in diameter capable of reaching $1100{ }^{\circ} \mathrm{C}$. The gas pressure inside the chamber was controlled by a throttle valve in conjunction with a pressure controller. The system controlled the furnace temperature to \pm $0.5^{\circ} \mathrm{C}$ at $1000{ }^{\circ} \mathrm{C}$, gas flow rate to $\pm 0.05 \mathrm{sccm}$ at $10 \mathrm{std}$. sccm, and system pressure to \pm 0.01 Torr at 330 and 450 Torr. The temperature profile within the chamber when the furnace was set at $1000{ }^{\circ} \mathrm{C}$ was accurately determined by a single thermocouple moved down the length of the furnace, with measurements made at $2 \mathrm{~cm}$ intervals. A parabolic fit to the furnace temperature data gave an $R^{2}$ value of 0.99 .

$\mathrm{Cu}$ discs on a sample boat were placed in the quartz tube in the middle of the chamber. Before starting, the chamber was flushed three times with $\mathrm{Ar}$ gas. The $3 \mathrm{DiGn}-\mathrm{Cu}$ composites were synthesized following the experimental conditions shown in Fig. 3. The specimen was cooled at a rate of approximately $200{ }^{\circ} \mathrm{C} / \mathrm{min}$ and was removed from the furnace when it reached to room temperature. The purpose of using $\mathrm{H}_{2}$ gas at $400{ }^{\circ} \mathrm{C}$ for $1 \mathrm{~h}$ in this experiment was to remove oxides and produce a high-surface-area $\mathrm{Cu}$ powder product that could react readily with carbon.

\subsection{Thermal conductivity measurements}

Accurate measurements of the thermal properties (thermal diffusivity and specific heat) and the mass of a sample are important for the eventual determination of its TC. The thermal diffusivity of the $3 \mathrm{DiGn}-\mathrm{Cu}$ composite was measured using the NETZSCH LFA 447 based on a wellknown method. In this method, the front side of a planeparallel sample is heated by a short light pulse. The resulting temperature rise on the rear surface is measured using an infrared detector, according the Parker's law [28]. By 


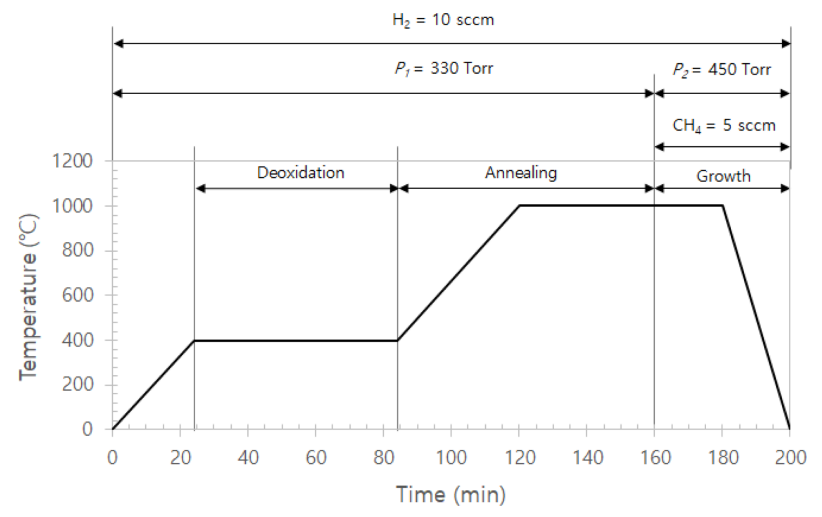

Fig. 3. Experimental conditions for the synthesis of the $3 \mathrm{DiGn}-\mathrm{Cu}$ composite.

analysis of the resulting temperature-versus-time curve, the thermal diffusivity can be determined. Additionally, heat capacity is measured by a TA instrument DSC Q2000. The densities of the 3DiGn-Cu composites were measured using Archimedes principle with a special electronic scale (Mettler Toledo), and the densities of the compacted $\mathrm{Cu}$ discs were estimated by measuring their dimensions (diameter and thickness) and weights after $\mathrm{Cu}$ powder compaction. Therefore, the thermal conductivity $(k)$ was calculated using $k=\alpha \rho C_{p}$, where $\alpha$ is the thermal diffusivity, $C_{p}$ is the specific heat, and $\rho$ is the bulk density of the sample.

\section{RESULTS AND DISCUSSION}

In addition to the changes in thickness and diameter, the densities of the three compacted $\mathrm{Cu}$ discs at each compacting pressure were estimated and compared to the measured densities of the 3DiGn-Cu composites after CVD, as shown in Fig. 4. To avoid any contamination during the synthesis of the 3DiGn-Cu composites, we did not use any lubricant for the particle compaction. During compaction at high pressures $(\geq 2500 \mathrm{~kg})$, the $\mathrm{Cu}$ particles at the disc surface experience relatively more plastic deformation than those inside the disc because of the friction force between particles. As a result, the particles of the discs compacted at higher pressures were less dense on the inside than at the disc surface. During CVD at $1000{ }^{\circ} \mathrm{C}$, the particles grow to reduce the surface energy as a result of $\mathrm{Cu}$ diffusion. The inner particles have longer diffusion distances owing to their lower density, which leaves pores among them due to a lack of sufficient diffusion or

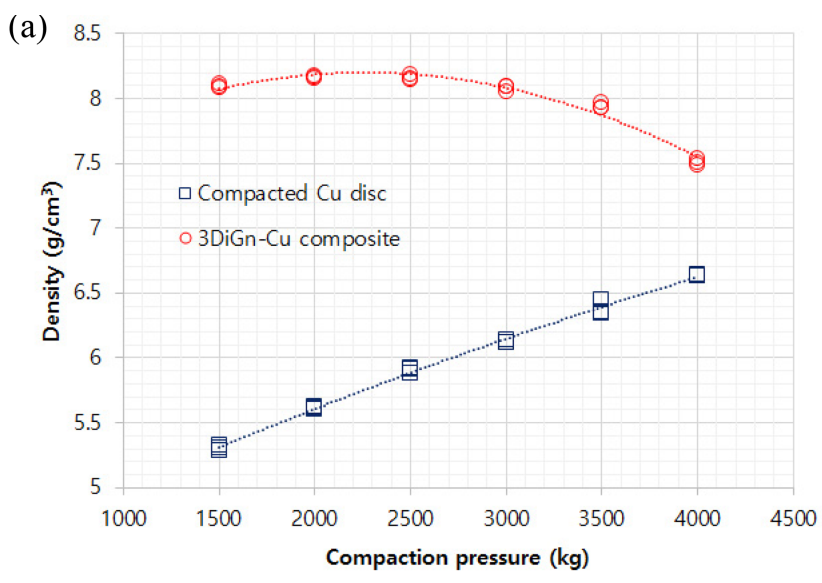

(b)

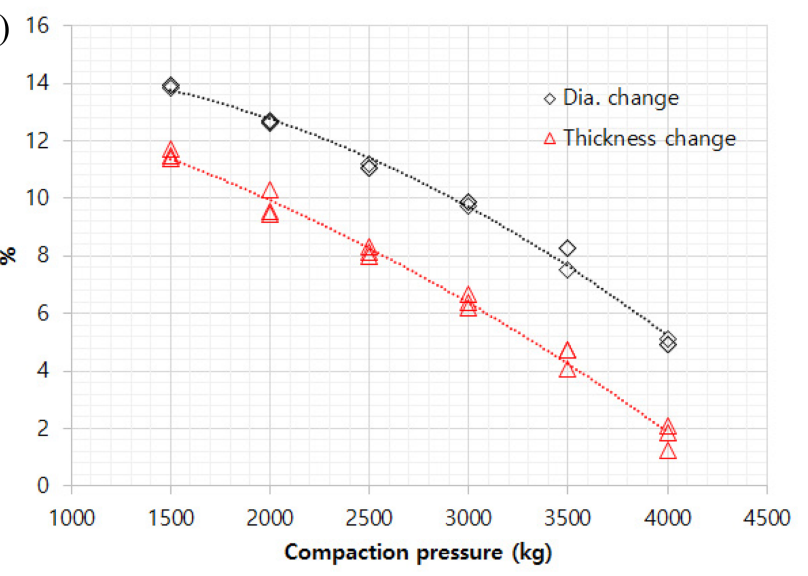

Fig. 4. Comparison of (a) densities and (b) changes in diameter and thickness of discs before (compacted $\mathrm{Cu}$ discs) and after (3DiGn-Cu composites) CVD depending on the compacting pressure (kg).

sintering time. This explains why the densities and dimensional changes (diameter and thickness) of the 3DiGn$\mathrm{Cu}$ composites decreased with increasing compaction pressure, whereas the densities of the compacted $\mathrm{Cu}$ discs increased. Furthermore, the three- dimensionally interconnected graphene network (3DiGn) formed at the $\mathrm{Cu}$ grain boundaries can act as a barrier not only to $\mathrm{Cu}$ diffusion but also to dislocation movement, thus preventing grain growth and increasing the strength of the composite [26].

Figure 5 shows a schematic diagram of the synthesis of the 3DiGn-Cu composite [25]. At the initial stage of CVD, carbon diffuses relatively easily through the boundaries of the $\mathrm{Cu}$ particles, thereby reaching every part of the $\mathrm{Cu}$ disc; with the diffusion coefficient (D) of $\sim 139 \mu \mathrm{m}^{2} / \mathrm{s}$ at $1030{ }^{\circ} \mathrm{C}$ [29], $\sim 6 \mathrm{ppm}$ of carbon dissolved into the $\mathrm{Cu}$ particles at $1000{ }^{\circ} \mathrm{C}$ [30]. The diffusion of $\mathrm{Cu}$ among the $\mathrm{Cu}$ particles results in reduced volume and the growth of $\mathrm{Cu}$ particles due to the 


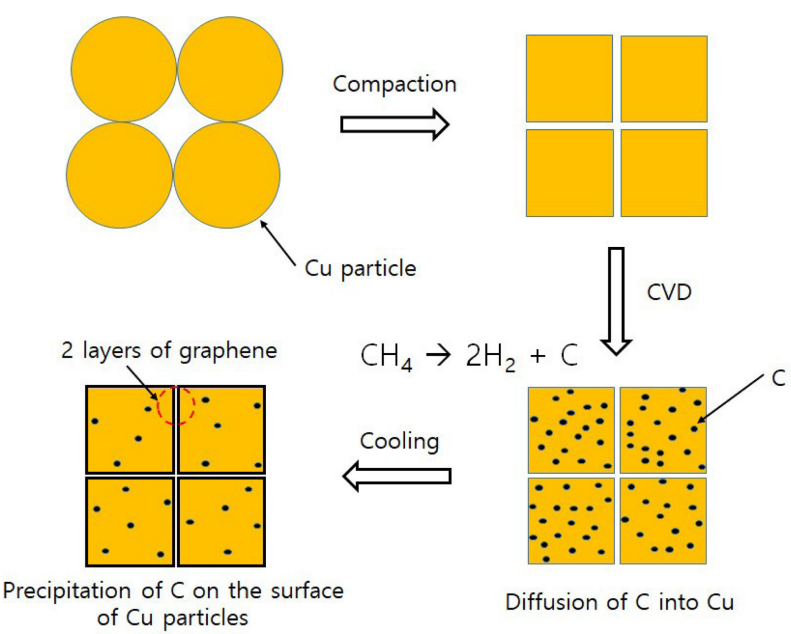

Fig. 5. Schematic diagram of the synthesis of $3 \mathrm{DiGn}-\mathrm{Cu}$ composite. Redrawn with permission from [25].

driving force to reduce the surface energy in the middle stage. At the last CVD stage, carbon precipitates out from neighboring $\mathrm{Cu}$ particles, resulting in the formation of graphene, mostly in two layers at grain boundaries during cooling. The graphene in the $3 \mathrm{DiGn}-\mathrm{Cu}$ composites forms at $\mathrm{Cu}$ grain boundaries and thus is connected continuously in three dimensions throughout the $\mathrm{Cu}$ matrix. Figure 6 shows TEM images of the graphene on $\mathrm{Cu}$. The grain above graphene was removed by electrolyte thinning and polishing with a Struers TenuPol-5 [25]. The graphene exhibited a good attachment to the underlying $\mathrm{Cu}$ matrix.

A Raman spectral analysis was performed and reported previously [25] for 3D graphene, which was prepared by etching $\mathrm{Cu}$ completely from the $3 \mathrm{DiGn}-\mathrm{Cu}$ composite to leave only the 3D graphene as shown in Fig. 7. Details regarding sample preparation and analytical procedures can be found elsewhere [25]. The Raman analysis showed that the intensity ratio of the $2 \mathrm{D}$ to $\mathrm{G}$ peaks was approximately 1 , indicating that the 3D graphene had mostly 2 layers. In addition, the relative intensities of the $\mathrm{D}$ to $\mathrm{G}$ peaks $(\sim 0.22)$ reflect the high quality of the graphene with few defects [31-33].

To determine the TCs of the 3DiGn-Cu composites, we examined their thermal properties by measuring the thermal diffusivity using laser flash analysis and specific heats with differential scanning calorimetry analysis. To obtain a high TC by utilizing graphene in metal matrix composites, the graphene should be sufficiently aligned with the metal matrix [20]. Furthermore, high-quality graphene with minimized

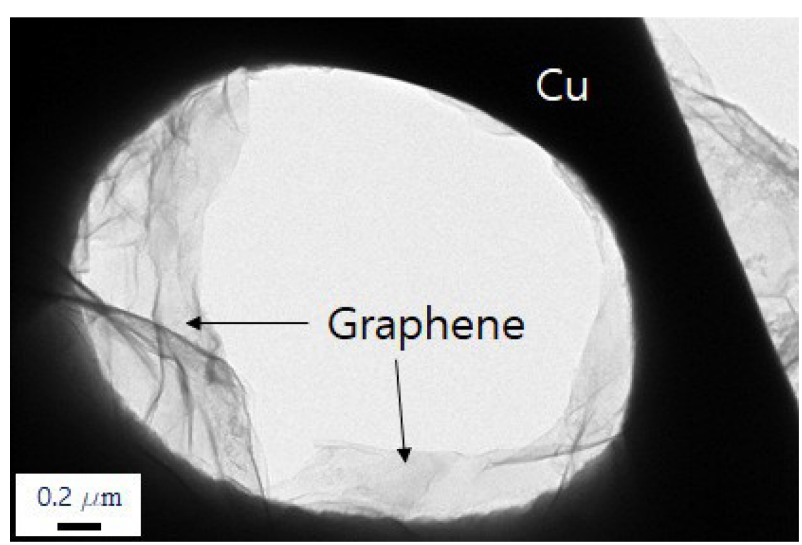

Fig. 6. TEM images of graphene formed at $\mathrm{Cu}$ grain boundaries.

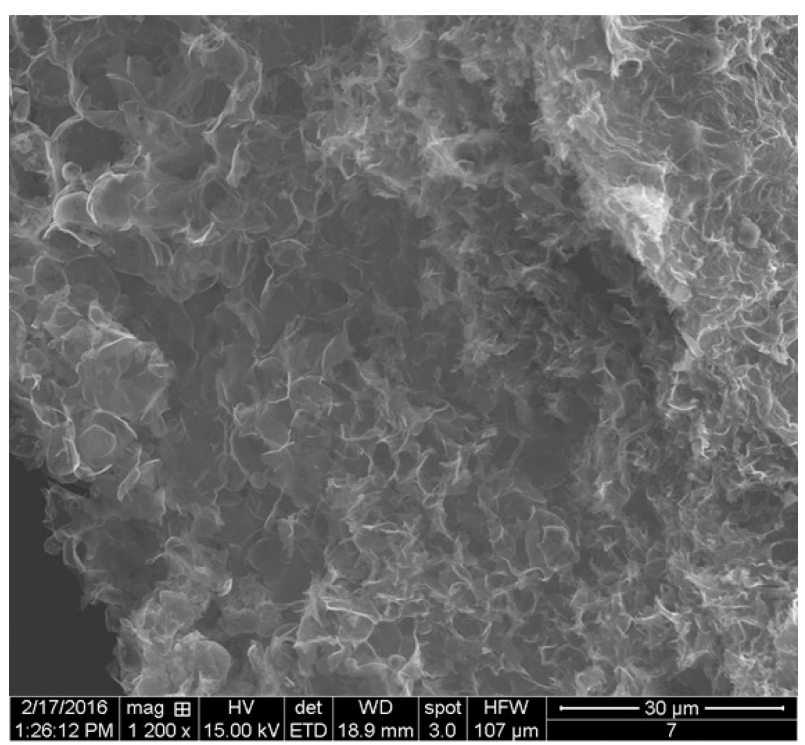

Fig. 7. SEM image of three-dimensionally interconnected graphene network (3DiGn).

defects is also essential for graphene-metal matrix composites, as defects naturally act as phonon-scattering centers and thus degrade the TCs of graphenes and their composites [9,35].

The carbon contents were measured using the ELTRA CS2000 analyzer with a precision of $\pm 0.3 \mathrm{ppm}$. The density vs. carbon content of the 3DiGn-Cu composites is plotted in Fig. 8 , and shows that the amount of carbon in the $3 \mathrm{DiGn}-\mathrm{Cu}$ composites decreases with increasing density of the same composites. A parabolic fit to the density vs. carbon content data provided an $R^{2}$ value of 0.99 . The relationship of TCs to the amount of carbon in the $3 \mathrm{DiGn}-\mathrm{Cu}$ composites is shown in Fig. 9. The figure shows that as the amount of carbon decreases, the TCs of the 3DiGn-Cu composite increase; 


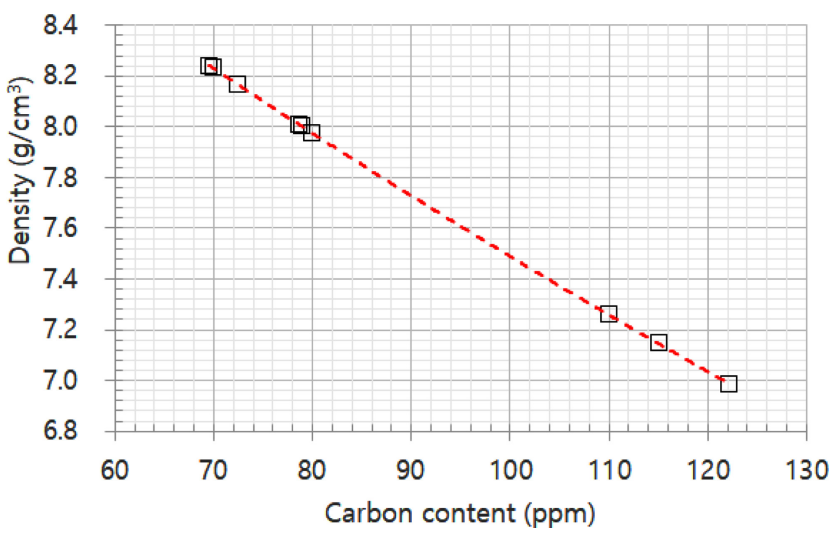

Fig. 8. Density vs. carbon content of 3DiGn-Cu composites.

however, the maximum $\mathrm{TC}$ of $406 \pm 5 \mathrm{~W} / \mathrm{mK}$ in the $3 \mathrm{DiGn}-$ $\mathrm{Cu}$ composite was obtained at a carbon content of $\sim$ $73 \mathrm{ppm}$. A further decrease in the amount of carbon resulted in a decrease in TC, indicating that there is a threshold for the amount of carbon to obtain the maximum TC in $3 \mathrm{DiGn}-\mathrm{Cu}$ composites.

The thermal properties of the $3 \mathrm{DiGn}-\mathrm{Cu}$ composite and $\mathrm{Cu}$ without graphene were measured between room temperature and $100{ }^{\circ} \mathrm{C}$ and are presented in Fig. 10. For comparison, the $\mathrm{Cu}$-only sample was prepared by the same method used for the preparation of the $3 \mathrm{DiGn}-\mathrm{Cu}$ composites, but without $\mathrm{CH}_{4}$ gas, during CVD. For the 3DiGn-Cu composite with a density of $8.16 \mathrm{~g} / \mathrm{cm}^{3}$ and carbon content of $\sim 73 \mathrm{ppm}$, enhanced TCs of $406 \pm 5 \mathrm{~W} / \mathrm{mK}$ and $385 \pm 7 \mathrm{~W} / \mathrm{mK}$ in the through- and in-plane directions, respectively, were obtained at room temperature. For in-plane $\mathrm{TC}$, the temperature rise on the rear surface was measured at three different positions $(5,10$, and $13 \mathrm{~mm}$ from the center of disc) and averaged. Therefore, the lower in-plane TC compared with the through-plane TC could be attributable to the increased number of defects as the measurement distance increased from $0.9 \mathrm{~mm}$ (through-plane) to $13 \mathrm{~mm}$ (in-plane). For comparison, the through-plane $\mathrm{TC}$ of $\mathrm{Cu}$ without graphene was measured as $125 \pm 5 \mathrm{~W} / \mathrm{mK}$, which is almost thrice lower than that of the 3DiGn-Cu composite.

Many studies have indicated that the volume fraction of carbon, its spatial distribution, and carbon-matrix interphase properties affect the macroscopic TC of graphene-metal composites [35]. Therefore, it is reasonable to conclude that the spatial distribution of the three-dimensionally interconnected continuous graphene network throughout the

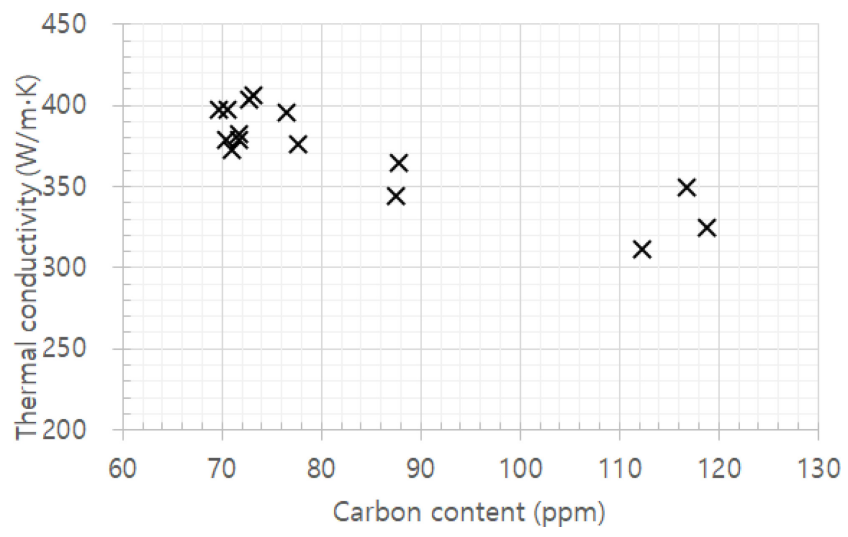

Fig. 9. TCs vs. carbon content of 3DiGn-Cu composites.

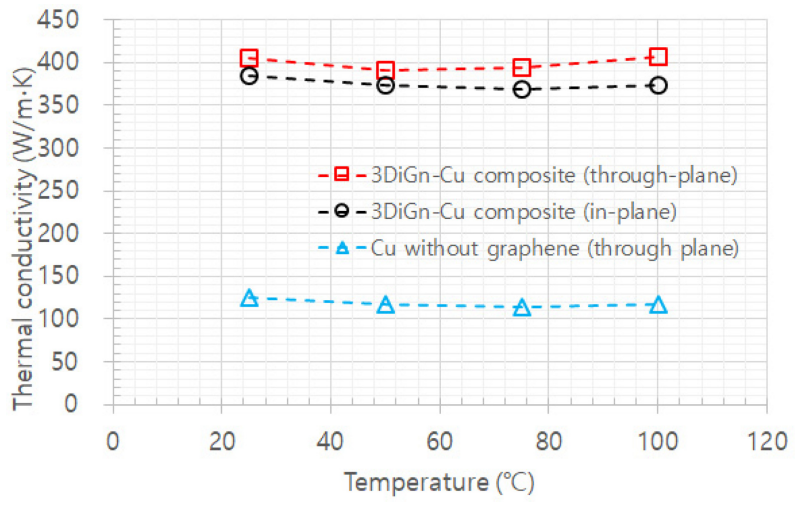

Fig. 10. TCs of 3DiGn-Cu composite and $\mathrm{Cu}$ without graphene.

$\mathrm{Cu}$ matrix must pro- vide effective pathways for thermal conduction in the $3 \mathrm{DiGn}-\mathrm{Cu}$ composite, resulting in a relatively high TC. However, the mechanism involved in the thermal conduction of $3 \mathrm{DiGn}-\mathrm{Cu}$ in relation to the radius of curvature for the $3 \mathrm{DiGn}$, i.e., bent, anchored, and wrapped around $\mathrm{Cu}$ grains, is not known. Therefore, it is necessary to further investigate the $\mathrm{TC}$ of the $3 \mathrm{DiGn}-\mathrm{Cu}$ composite in relation to the shape of graphene.

\section{CONCLUSION}

We demonstrated a three-dimensionally interconnected graphene-networked $\mathrm{Cu}$ (3DiGn-Cu) composite fabricated by a simple two-step process: compaction of $\mathrm{Cu}$ powder with 99\% purity followed by CVD. The fabrication process and Raman analysis of the 3DiGn-Cu composite indicated the precipitation of carbon from neighboring $\mathrm{Cu}$ particles, which resulted in the formation of (typically) 2 layers of graphene 
at the $\mathrm{Cu}$ grain boundaries. Lastly, the enhanced through-/inplane TCs indicate that the three-dimensionally interconnected graphene network (3DiGn) in a $\mathrm{Cu}$ metal matrix provides effective pathways for thermal conduction. Therefore, even though the TC obtained herein is not as high as that recently reported, it is worth considering this new and easy fabrication method for 3DiGn-Cu composites and its possibilities for numerous applications. To achieve a sufficiently high TC in the $3 \mathrm{DiGn}-\mathrm{Cu}$ composite comparable to the TC of graphene, our ongoing research will focus on not only fabricating 3DiGn but also on the shape and quality of graphene in the 3DiGn-Cu composite.

\section{ACKNOWLEDGEMENT}

This work was supported by research funds from Chosun University, 2016.

\section{REFERENCES}

1. K. M. F. Shahil and A. A. Balandin, Solid State Commun. 152, 1331 (2012).

2. T. Kuilla, S. Bhadra, D. Yao, N. H. Kim, S. Bose, and J. H. Lee, Polym. Sci. 35, 1350 (2010).

3. M. A. Raza, A. Westwood, and C. Stirling, Mater. Des. 85 , 67 (2015).

4. Y. Song, J. Yu, L. Yu, F. E. Alam, W. Dai, C. Li, and N. Jiang, Mater. Des. 88, 950 (2015).

5. T. K. Das and S. Prusty, Polym. Plast. Techanol. Eng. 52, 319 (2013).

6. V. Goyal and A. A. Balandin, Appl. Phys. Lett. 100, 073113 (2012).

7. K. Jagannadham, Metall. Mater. Trans. B 43, 316 (2012).

8. K. S. Novoselov, V. I. Fal'ko, L. Colombo, P. R. Gellert, M. G. Schwab, and K. Kim, Nature 490, 192 (2012).

9. A. A. Balandin, S. Ghosh, W. Bao, I. Calizo, D. Teweldebrhan, F. Miao, and J. Lau, Nano Lett. 8, 902 (2008).

10. A. A. Balandin, Nat. Mater. 10, 569 (2011).

11. X. Yang, Z. Wang, M. Xu, R. Zhao, and X. Liu, Mater. Des. 44, 74 (2013).

12. M. E. Achaby and A. Qaiss, Mater. Des. 44, 81 (2013).

13. A. K. Geim, Science 324, 1530 (2009).

14. I.-J. Shon, Korean J. Met. Mater. 55, 110 (2017).
15. S. Kim, H-C. Kwon, D. Lee, and H-S. Lee, Met. Mater. Int. 23, 1144 (2017).

16. A. Saboori, E. Padovano, M. Pavese, H. Dieringa, and C. Badini, Materials 10, 1380 (2017).

17. E. Neubauer, M. Kitzmantel, M. Hulman, and P. Angerer, Compos. Sci. Technol. 70, 2228 (2010).

18. J. Renteria, S. Legedza, R. Salgado, M. P. Balandin, S. Ramirez, M. Saadah, F. Kargar, and A. A. Balandin, Mater. Des. 88, 214 (2015).

19. J. D. Renteria, S. Ramirez, H. Malekpour, B. Alonso, A. Centeno, A. Zurutuza, A. I. Cocemasov, D. L. Nika, and A. A. Balandin, Adv. Funct. Mater. 25, 4664 (2015).

20. K. Chu, X. Wang, F. Wang, Y. Li, D. Juang, H. Liu, W. Ma, F. Liu, and H. Zhang, Carbon 127, 102 (2018).

21. D. E. Ellis, K. C. Mundim, D. Fuks, S. Dorfman, and A. Berner, Phil. Mag. B 79, 1615 (1999).

22. Y. Chen, X. Zhang, E. Liu, C. He, Y. Han, Q. Li, P. Nash, and N. Zhao, J. Alloy. Compd. 688, 69 (2016).

23. L. A. Yolshina, R. V. Muradymov, I. V. Korsun, G. A. Yakovlev, and S. V. Smirnov, J. Alloy. Compd. 663, 449 (2016).

24. F. Chen, J. Ying, Y. Wang, S. Du, Z. Liu, and Q. Huang, Carbon 96, 836 (2016).

25. S.-R. Kawk, T. A. Ring, and B.-S. Choi, J. Ind. Eng. Chem. 70, 484 (2019).

26. I. A. Ovid'ko, Rev. Adv. Mater. Sci. 38, 190 (2014).

27. Y. Y. Kim, H. J. Jang, and B. S. Choi, Korea Inst. Electro. Commun. Sci. 8, 549 (2013).

28. W. J. Parker, R. J. Jenkins, C. P. Butler, and G. L. Abbott, J. Appl. Phys. 32, 1679 (1961).

29. Z. Zhao, Z. Shan, C. Zhang, Q. Li, B. Tian, Z. Huang, W. Lin, X. Chen, H. Ji, W. Zhang, and W. Cai, Small 11, 1418 (2015).

30. C. Mattevi, H. Kim, and M. Chhowalla, J. Mater. Chem. 21, 3324 (2011).

31. Y. Chen, X. Zhang, E. Liu, C. He, C. Shi, J. Li, P. Nash, and N. Zhao, Sci. Rep. 6, 19363 (2016).

32. J. Hwang, T. Yoon, S. Y. Jin, J. Lee, T.-S. Kim, S. H. Hong, and S. Jeon, Adv. Mater. 25, 6724 (2013).

33. C. He, N. Zhao, C. Shi, X. Du, J. Li, H. Li, and Q. Cui, $A d v$ Mater. 19, 1128 (2007).

34. S. Chen, Q. Wu, C. Mishra, J. Kang, H. Zhang, K. Cho, W. Cai, and A. A. Balandin, Nat. Mater. 11, 203 (2012).

35. P. E. Hopkins, M. Baraket, E. V. Barnet, T. E. Beechem, S. P. Kearney, and J. C. Duda, Nano Lett. 12, 590 (2012). 